This document was prepared in conjunction with work accomplished under Contract No. DE-AC09-96SR18500 with the U.S. Department of Energy.

This work was prepared under an agreement with and funded by the U.S. Government. Neither the U. S. Government or its employees, nor any of its contractors, subcontractors or their employees, makes any express or implied: 1 . warranty or assumes any legal liability for the accuracy, completeness, or for the use or results of such use of any information, product, or process disclosed; or 2 . representation that such use or results of such use would not infringe privately owned rights; or 3 . endorsement or recommendation of any specifically identified commercial product, process, or service. Any views and opinions of authors expressed in this work do not necessarily state or reflect those of the United States Government, or its contractors, or subcontractors. 


\title{
Aerial Measurements of Convection Cell Elements in Heated Lakes
}

\author{
E. Villa-Aleman ${ }^{* a}$, S.R. Salaymeh ${ }^{\mathrm{a}}$, T.B. Brown ${ }^{\mathrm{a}}$, A.J. Garrett ${ }^{\mathrm{a}}$, L.S. Nichols ${ }^{\mathrm{a}}$, M.M. Pendergast ${ }^{\mathrm{a}}$, \\ ${ }^{\mathrm{a}}$ Savannah River National Laboratory, Aiken, SC, 29808, USA
}

\begin{abstract}
Power plant-heated lakes are characterized by a temperature gradient in the thermal plume originating at the discharge of the power plant and terminating at the water intake. The maximum water temperature discharged by the power plant into the lake depends on the power generated at the facility and environmental regulations on the temperature of the lake. Besides the observed thermal plume, cloud-like thermal cells (convection cell elements) are also observed on the water surface. The size, shape and temperature of the convection cell elements depends on several parameters such as the lake water temperature, wind speed, surfactants and the depth of the thermocline. The Savannah River National Laboratory (SRNL) and Clemson University are collaborating to determine the applicability of laboratory empirical correlations between surface heat flux and thermal convection intensity. Laboratory experiments at Clemson University have demonstrated a simple relationship between the surface heat flux and the standard deviation of temperature fluctuations. Similar results were observed in the aerial thermal imagery SRNL collected at different locations along the thermal plume and at different elevations. SRNL will present evidence that the results at Clemson University are applicable to cooling lakes.
\end{abstract}

Keywords: infrared imagery, aerial, convection cell elements, heat flux, nuclear power plant

\section{INTRODUCTION}

Conduction, convection and radiation heat losses occur from an object at a higher temperature to the surroundings. A phase change such as the evaporation of water also contributes to heat losses from a system. Water bodies in the environment such as a pond, lake or an ocean primarily lose heat through evaporation, convection and radiation processes. Convection can be classified in two types; natural and forced. For a water/air interface, forced convection primarily depends on the air wind speed. Heat loss through radiation process is determined by the temperature difference between the body and the surrounding (cold skies). These heat transfer processes result in a thermal instability on the water surface. The thermal instability on the water surface manifests itself in the formation of convection cell elements, which look like clouds with 0.1 to $\sim 2 \mathrm{C}$ temperatures above the water surface mean temperature. The morphology of the convection cell elements depends on several environmental parameters such as wind speed, air temperature, water temperature, relative humidity and depth of the thermocline since they affect heat transfer between one medium to another. Although the convection cell elements are not visible to the naked eye, their presence is evident in the infrared spectral region.

Conover et al. ${ }^{1}$ from Clemson University demonstrated a simple relationship between surface heat flux and the standard deviation (sigma) of the temperature fluctuations in an image. In order to determine the applicability of the heat transfer results at Clemson University to water bodies in the environment, three water body sites were selected to test the correlation between heat flux and sigma. The first site, D-Pond, is a small shallow retaining basin used by a coal power plant located at Savannah River Site (SRS). Two campaigns were conducted at D-Pond on March 2-3, 2006 and May 9, 2006. During this these campaigns, convection cell elements were identified and the morphology was correlated with wind speed and direction. The second site selected for these experiments was Lake Robinson, cooling lake for H.B Robinson Nuclear Power Plant.

*eliel.villa-aleman@srnl.doe.gov; 1803 725-0849 
Campaigns were conducted on August 8-9, 2006, February 21-22, 2007 and April 2-3, 2007. These campaigns collected imagery in conditions of moderate heat flux and in one case zero to slightly negative heat flux. Horizontal transects were conducted along the length of the lake showing for the first time the correlation of heat flux with water temperature in a natural water body. Elevation profiles were also acquired for the first time at Lake Robinson. Finally, the cooling lake for Comanche Peak Nuclear Power Plant was selected as the third site for these studies. An extended campaign from October 29, 30, 31 and November 1, 2007 was conducted at Comanche Peak. A high speed infrared camera (Jade 570L from CEDIP) was used for the first time to remove the helicopter motion blur from the infrared images often seen with the $60 \mathrm{~Hz}$ cameras. The images acquired with the long wave Jade camera enabled the acquisition of higher elevation profiles not seen previously with $60 \mathrm{~Hz}$ system. Comanche Peak data is still under analysis and detailed analysis will be left to a future research paper.

The large temperature difference between the water inlet and water outlet from the reactor $(>8 \mathrm{C})$ and temperature variability encountered in cooling lakes provided unique experimental conditions not found in the laboratory. The depth variability also encountered in different cooling lakes provides a way to conduct thermocline studies, e.g. Lake Robinson is a shallow lake a few meters deep while Comanche Peak average depth is approximately 30 meters.

This research paper provides an overview of some of the results acquired from the three water bodies. It is the goal of this research paper to present the experimental methodology and a glimpse of the correlation between heat flux and sigma computed from the acquired infrared images.

\section{EXPERIMENTAL}

The campaigns conducted at the three sites have a ground truth component and an aerial component. Experimental data from both components are required in order to establish the relationship between heat flux and sigma. Ground truth at the three sites was acquired with a Skin Temperature Rig apparatus. The Skin Temperature Rig apparatus ${ }^{2}$ measured water temperatures at 1,10 and $50 \mathrm{~cm}$ depths with a thermocouple ( $0.05 \mathrm{C}$ accuracy). The air temperature $(0.05 \mathrm{C})$ was measured at 0.7 and $0.35 \mathrm{~m}$ above the water surface. The relative humidity, wind speed and direction were measured with a 2-D sonic anemometer (3\% accuracy), fine wire thermocouple and humicap (4\% accuracy). The water surface temperature was measured with a radiometer (Heitronics, KT15.82) operating in the 8 - $12 \mu \mathrm{m}$ spectral region with 0.1C accuracy. The compass used in these experiments has an estimated accuracy of 2 degrees. Infrared imagery was also acquired by the ground truth team. The SC2000 Inframetrics camera was deployed approximately 5 meters above the water surface. At D-Pond, a tower was deployed next to the pond's shore to acquire imagery. Ground truth at Lake Robinson and Comanche Peak required a boat to deploy the Skin Temperature Rig apparatus and to obtain water surface imagery. A tower was assembled in the boat to elevate the camera $5 \mathrm{~m}$ from the water surface. Infrared imagery was acquired every minute during the course of the experiment.

A helicopter was used to acquire aerial infrared imagery over the selected water bodies. At SRS, the Aviation Operation Department of Wackenhut Services, Inc. made accessible the BK117 American Eurocopper for aerial infrared imagery of SRS D-Pond. Helicopter services were contracted to fly over Lake Robinson and Comanche Peak lakes. In both campaigns, a Robinson R44 helicopter was used to acquire the infrared images. Permission from the power plants was required in order to fly over the lake air space. Several methods were used to acquire infrared imagery from the helicopter and to ensure that the helicopter downwash did not affect the convection cell elements. Infrared images over the water body at areas of interest were acquired with the helicopter hovering for approximately a minute. Downwash from the helicopter hovering at low elevation $(<100 \mathrm{~m})$ affected the water surface. The effect of helicopter downwash was eliminated or reduced by flying the helicopter sideways and taking the imagery prior to the downwash effect.

Three infrared cameras (Inframetrics SC2000, FLIR S65HS and CEDIP Jade 570L) were used during the course of this project. The Inframetrics SC2000 has a focal plane array (320 x 240 pixels) uncooled microbolometer operating in the 7.6 - $13.5 \mu \mathrm{m}$ spectral range. The NEDT and field of view of the camera is $100 \mathrm{mK}$ and $26^{\circ} \mathrm{H} \mathrm{x} 19.5^{\circ} \mathrm{V}$, respectively. The instantaneous field of view (IFOV) is $1.4 \mathrm{mrad}$ which corresponds to $14 \mathrm{~cm}$ from an elevation of $100 \mathrm{~m}$. The FLIR S65HS has a focal plane array ( $320 \times 240$ pixels) uncooled microbolometer operating in the $7.5-13 \mu \mathrm{m}$ spectral range. The NEDT and field of view of the camera is $50 \mathrm{mK}$ and $18.7^{\circ} \mathrm{H} \mathrm{x} 14.2^{\circ} \mathrm{V}$, respectively. The IFOV is $1.1 \mathrm{mrad}$


The corresponding spatial resolution is $5.3 \mathrm{~cm}$ at $100 \mathrm{~m}$. The infrared camera, Jade 570L, has a cooled MCT (mercury 
cadmium telluride) focal plane array (320 x 240 pixels) operating in the 7.7 - $9.5 \mu \mathrm{m}$ spectral range. The NEDT and field of view of the camera is $<20 \mathrm{mK}$ at $30 \mathrm{C}$ and $11^{\circ} \mathrm{H} \mathrm{x} 8^{\circ} \mathrm{V}$, respectively. The corresponding spatial resolution is $5.2 \mathrm{~cm}$ at $100 \mathrm{~m}$.

Imagery acquisition at D-Pond was conducted from $45 \mathrm{~m}$ to $152 \mathrm{~m}$ above the pond. In the early campaigns at D-Pond and Lake Robinson, the Inframetrics SC2000 and the FLIR S65HS infrared cameras were used to acquire images. The wide field of view in the SC2000 and in the FLIR S65HS infrared cameras made it difficult to view the water surface without the interference of the helicopter skid. Since the helicopter skid was in the field of view of the camera, images were recorded with a slanted angle. A 2x zoom lens for the S65HS infrared camera was procured and used in later campaigns at Lake Robinson and Comanche Peak. The zoom lens produced a $9.6^{\circ} \mathrm{H} \mathrm{x} 7.2^{\circ} \mathrm{V}$ field-of-view. The zoom lens enabled us to image the lake between the helicopter body and the skid in the nadir direction.

Also, in the initial phase of this project, images were acquired one shot at time by the camera operator. Blurred images were one of the problems often encountered due to the helicopter motion. Blurred images affect the computation of sigma. In order to increase the number of good images from a location, the camera was connected to a computer for real time acquisition. Under these conditions, the camera holder pointed the camera to the water surface between the helicopter body and the skid while the camera operator acquired 100 images at $60 \mathrm{~Hz}$. A significant number of unblurred images were available for data analysis from the 100 images recorded at a given location. The acquisition time of these images was $16 \mathrm{~ms}(1 / 60 \mathrm{~Hz})$. ThermaCam Researcher software was used to analyze the imagery acquired with the Inframetrics SC2000 and FLIR S65HS infrared cameras. A new high speed camera was introduced into the final campaign at Comanche Peak. The Jade 590 infrared camera manufactured by CEDIP Corporation was operated at $240 \mathrm{~Hz}$ with 250 microsecond integration time. The short integration time $(250 \mu \mathrm{m})$ of the Jade camera enabled the acquisition of events 64 times faster than with the S65HS camera (16000/250). Blurring effects were not noticeable with the new Jade camera under our experimental conditions. Altair software was used to control and process the imagery.

The experimental methodology at Lake Robinson and Comanche Peak was very similar. Several locations along the lake were selected for study. The GPS coordinate of the location above the water surface was recorded for data processing. Transects of the lake were conducted at $91 \mathrm{~m}$ and $152 \mathrm{~m}$. Elevations profiles were also obtained from $15 \mathrm{~m}$ up to $1219 \mathrm{~m}$ above a given surface. Elevation profiles with the Jade camera were sharper than the elevation profiles obtained with the S65HS camera. Once the imagery was acquired, the images were filtered with a tailored high frequency band pass filter to eliminate low frequency components due to lens vignetting. Another low frequency band pass filter was applied to eliminate bad pixels. Once the band pass filters were applied, the standard deviation was computed. The heat flux computed from data acquired by the ground team was compared with the standard deviation computed from the infrared images ${ }^{3}$.

\section{RESULTS AND DISCUSSIONS}

D-Pond at SRS is shown in Figure 1a. Figure 1b shows an infrared image of D-Pond from a helicopter at $152 \mathrm{~m}$ from the ground. The water inlet is located in the upper left side of the pond (Fig. 1b) while the water outlet is in the bottom left side. The linear feature in the center of Figure $1 \mathrm{~b}$ is a dirt road. The cloudy-like features observed on the water surface are the convection cell elements formed during the heat exchange. The convection cell elements are the product of heat transfer from the water body to the environment. The primary thermodynamic processes in play during the formation of the convection cell elements are: convection between water surface and air, phase change through the evaporation of water and radiation losses. The loss of heat at the water surface destabilizes the upper water layer which leads to the formation of buoyant convective cells.

The deployment of the infrared camera by the ground team is shown in Figure 1C. A closer view of the convection cell elements with the ground team infrared camera reveals the finer structure of the convection cell elements. Figure 2a shows a comparison of the image data recorded by the ground team with an image acquired by Conover et al. at Clemson University. These images were acquired with no wind speed. Figure $2 \mathrm{~b}$ shows the infrared images with the effect of wind. The convection cell elements align in the direction of the wind. Several campaigns were conducted at the discharge basin under different atmospheric conditions. The infrared camera (SC2000) was positioned $6 \mathrm{~m}$ above the water surface. The data acquired at D-Pond by the ground team and the aerial imagery clearly shows the existence of 
a correlation between the heat flux and the standard deviation computed from the infrared images. This is the first time that the heat flux/sigma correlation has been tested for water bodies in the environment.

Lake Robinson, the cooling lake for the H.B. Robinson Nuclear Power Plant located in South Carolina, was used as a second site for the hypothesis test. Figure 3 shows a satellite image with the selected locations marked along the lake and a mosaic composed of infrared images of the cooling lake from a $1500 \mathrm{~m}$ elevation. The mosaic was made out of 5 infrared images acquired with an Inframetrics 760 infrared camera in 1999. The H.B. Robinson cooling lake is approximately $8 \mathrm{~km} \mathrm{x} 1 \mathrm{~km}$. The outlet water from the reactors travels along the canal for approximately $6.2 \mathrm{~km}$ into the lake.





Fig. 2a. Left image corresponds to an infrared image of D-Pond at $6 \mathrm{~m}$ above the water surface with no wind. The image on the right is a laboratory image with no wind.


Fig. 2b. Left image corresponds to an infrared image of DPond at $6 \mathrm{~m}$ above the water surface with wind. The image on the right is a laboratory image with wind. Convection cell elements align along the wind direction. 
The reactor hot water discharge cools off through radiation, convection and evaporation processes in the way back to the inlet of the power plant. At Lake Robinson, aerial surveys were conducted at 91 and $152 \mathrm{~m}$ above the water surface. Approximately 12 locations were selected along the lake length per transect. Elevation profiles were also conducted to determine the effect of spatial resolution in the computation of the standard deviation statistics and the heat flux. The primary factors affecting the shape of the convection cell elements and therefore the standard deviation statistics are temperature and wind. Large temperature differences between water and air are responsible for intense convection cell elements with large standard deviations. Wind changes the shape of the convection cell elements into elongated chains with smaller standard deviations. Figure 4 shows the convection cell elements observed in the outlet canal. In general, the standard deviation at Lake Robinson was below 0.2. A significantly higher sigma was observed in the discharge canal. The ground truth boat, equipped with an infrared camera (SC2000), was stationed near the outlet of the canal. The Skin Temperature Rig apparatus already described for D-Pond was deployed approximately $100 \mathrm{~m}$ away from the boat. The Skin Temperature Rig and the boat with the camera are shown in Figure 5. The instrumentation available in the Skin Temperature Rig apparatus was duplicated in the boat at the Comanche Peak campaign.



Fig. 3. Left image is a visible satellite image with the selected areas marked with yellow triangles. The corresponding infrared image is shown on the right.



Fig. 4. Convection cell elements imaged from $31 \mathrm{~m}$ above the water surface at the discharge canal of Lake Robinson. A standard deviation of $0.54 \mathrm{C}$ was computed from this image. The yellow area is hotter than the red colors in the image.

The collection methodology included a flight to a selected location followed by orientation against the wind, hovering over the place and the acquisition of several images. The GPS coordinates were also acquired prior to leaving the location. Figure 6 shows the convection cell elements near the boat and the Skin Temperature Rig apparatus. A helicopter, Robinson R44 shown in Figure 7, was used to collect infrared imagery at the points indicated in Figure 3. The standard deviation of the images acquired at $30 \mathrm{~m}$ and $120 \mathrm{~m}$ are indicated in the infrared images. The effect of the boat on the water surface is also clear from the image. Figure 8 shows raw infrared images at different locations at Lake Robinson. The raw infrared imagery requires further processing in order to correct for several camera and lens vignetting artifacts. The imagery correction process will be presented by Garrett et al. ${ }^{3}$ in the SPIE Thermosense XXX conference. Figure 9 shows the imagery acquired during February 2007 campaign at Lake Robinson. Weather conditions prior to this collection led to zero or negative heat fluxes at the cold end of the lake and positive heat fluxes at the hot end of the lake. Heat fluxes at the different locations are annotated in the images. Figure 10 shows the 
correlation of between the heat flux and the standard deviation from data acquired at Lake Robinson during the April 2007 campaign. The $\mathrm{R}^{2}$ computed from the data was 0.78 , a very good value for environmental measurements.



Fig. 5. The left picture shows the boat with the infrared camera attached to a mast and the Skin Temperature Rig. The right picture shows an up-close image of the rig.








Fig. 7. Robinson R44 helicopter used in the Lake Robinson campaigns.
In contrast to the shallow Lake Robinson (3 meter deep average) in South Carolina, Comanche Peak is a 30 meter deep lake. The correspondingly deeper thermocline layer should enlarge the size of the convection cell elements observed in the infrared. Eight horizontal transects and five vertical profiles were conducted at Comanche Peak between October 29 and November $1^{\text {st }}$, 2007. The S65HS infrared camera was used in three horizontal and one vertical while the Jade camera from CEDIP was used in the remaining five horizontal transects and four vertical profiles. The horizontal transects were conducted at two elevations; 91 and $152 \mathrm{~m}$. The convection cell elements were evident from the infrared imagery. Although the interrogation locations at Lake Robinson were selected along the length of the lake, most of the locations at Comanche Peak were at the lake branches. The lake branches, in many cases surrounded by hills, introduced variability in the computed sigma due to the wind effect on the morphology of the convection cell elements. Therefore, different convection cell elements with round and elongated shapes were observed due to the wind speed and temperature. The addition of the high speed Jade 570L camera enabled us for the first time to eliminate the blur caused by the helicopter motion. Spatial resolution was not affected by the helicopter motion and enabled us to conduct elevation profiles over a given location up to $1219 \mathrm{~m}$ above the water surface. The data and imagery at Comanche Peak is still under analysis.



Figure 11 shows the quality of the most recent infrared imagery under helicopter motion. The images were acquired while flying $6 \mathrm{~m}$ above the water surface and acquiring the imagery prior to the helicopter downwash. The images in Figure 11 were recorded at 7.6, 15.2, 30.5, 91.4, 152.4, and 305 meters. Images at other elevations not shown in Figure 11 were at 457, 610, 762, 914, 1067, and 1219 meters. Although not shown, the relationship between heat flux and sigma was also computed by Garrett et al. ${ }^{3}$ for elevation profiles conducted at Lake Robinson campaigns. 

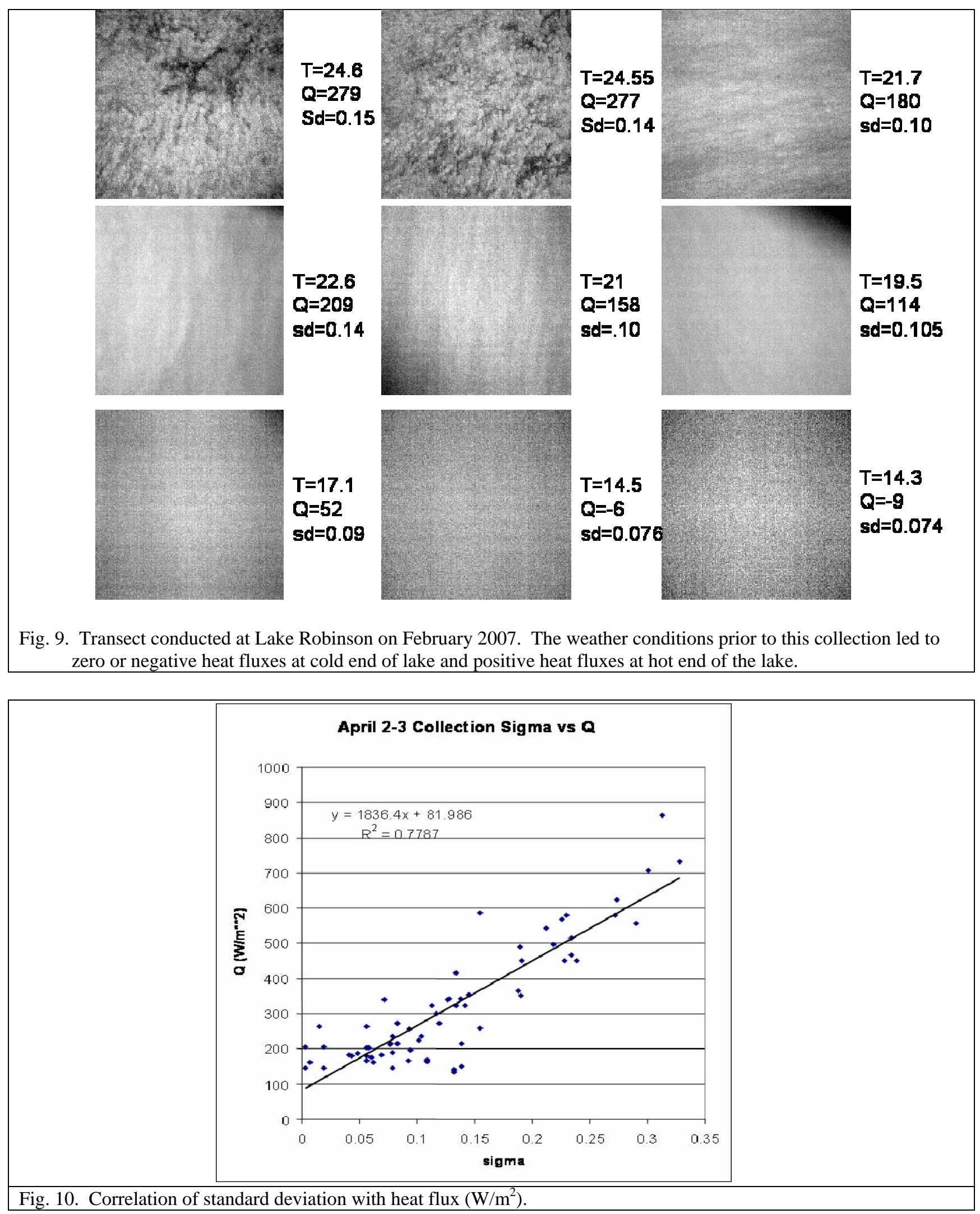




elevation: $7.6 \mathrm{~m}$



elevation: $91.4 \mathrm{~m}$



elevation: $15.2 \mathrm{~m}$

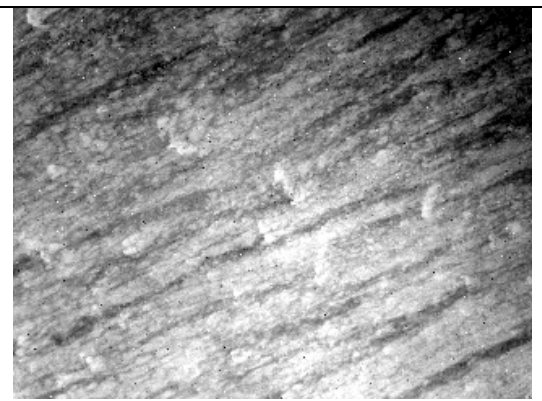

elevation: $152.4 \mathrm{~m}$



elevation: $30.5 \mathrm{~m}$

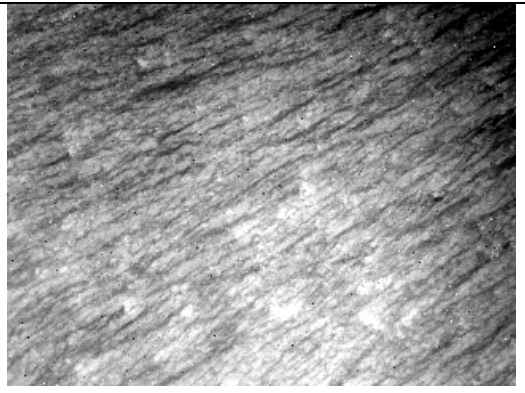

elevation: $305 \mathrm{~m}$

Fig. 11. Elevation profile over selected region at Comanche Peak cooling lake. The images below 30 meters were acquired while the helicopter was moving over the surface to eliminate the downwash. The elevation profile was recorded up to 1220 meters.

\section{SUMMARY}

The simple relationship between heat flux and the temperature standard deviation of an infrared image was investigated in large water bodies such as ponds and heated lakes. Nuclear power plants-heated lakes were investigated due to the large variability in the heat flux from the inlet to the outlet of the reactor. The effect of the wind on the morphology of the convection cell elements was also investigated in extended campaigns at different times of the year. The thermocline effect on the heat flux was also investigated by choosing two lakes with significant differences in the depth of the thermocline. The relationship between standard deviation of temperatures in an infrared image with elevation above the water surface ranging from 5 to 1220 meters was also studied during the course of this project. The data acquired in these campaigns clearly show a simple relationship between the heat flux and the standard deviation of the temperatures in an image.

\section{ACKNOWLEDGMENTS}

SRNL would like to express gratitude to H.B Robinson Nuclear Power Plant and Comanche Peak Nuclear Power Plant for their support in this Department of Energy basic research project. SRNL will also like to express gratitude to the Aerial Division of Wackenhut Services at SRS for providing helicopter services for D-Pond work.

\section{REFERENCES}

1. T.A. Conover and J.R. Saylor, "Statistics of the surface temperature field of an air/water interface under air flow,” Experimental Fluids (2007) 43:509-524

2. R. Kurzeja, M.M. Pendergast, E. Villa-Aleman, "Measurements of the Skin Temperature on Small Lakes," Journal of Atmospheric and Oceanic Technology, (2005) 22:1423-1432.

3. A. J. Garrett, E. Villa-Aleman, R.J. Kurzeja, M.M. Pendergast, J. Saylor; "Direct measurement of heat flux from cooling lake thermal imagery," SPIE Defense and Security, Thermosense XXX. 